\title{
Percepções do impacto da pandemia no meio acadêmico da música: um ensaio aberto sobre temporalidades e musicalidades
}

\author{
Luciane Cuervo \\ Universidade Federal do Rio Grande do Sul, Instituto de Artes \\ luciane.cuervo@ufrgs.br \\ https://orcid.org/0000-0003-1697-6836 \\ Pedro Ricardo Bücker Santiago \\ Universidade Federal do Rio Grande do Sul, Instituto de Artes \\ pedrorbs@gmail.com \\ https://orcid.org/0000-0002-0724-3684
}

\begin{abstract}
Resumo: Este ensaio crítico discute o cenário da pandemia do COVID-19 e suas demandas no campo da educação superior em música, com especial atenção às noções de musicalidade e temporalidade. Toma como fundamento, além de estudos científicos, matérias vinculadas na mídia e veículos alternativos. Ilustram as reflexões os relatos coletados em levantamentos ocorridos no período de março a outubro de 2020 no ambiente virtual institucional de aprendizagem, buscando traçar dificuldades e superações observadas entre discentes nas suas relações com a musicalidade e seus estados emocionais. Resgatando dados sobre o impacto do ensino remoto e das novas tecnologias digitais nos estados emocionais deste público, o trabalho busca delinear as possibilidades e contrariedades das conexões em diferentes interfaces, seja afetiva, seja tecnológica. Este recorte temporal está dividido em três movimentos e traça ao final, numa abordagem otimista, caminhos realizáveis diante da imprevisibilidade e da instabilidade dessa nova realidade que se apresenta.
\end{abstract}

Palavras-chave: pandemia, cultura digital, emoções dos músicos, COVID-19.

\section{Perceptions of the impact of the pandemic on the academic environment of music: an open essay on temporality and musicality}

\begin{abstract}
This critical essay discusses the COVID-19 pandemic scenario and its demands in the field of Undergraduate Studies in Music, with special attention to the notions of musicality and temporality. It takes as a basis, in addition to scientific studies, news linked in the media and alternative vehicles. Reports collected in surveys carried out from March to October 2020 in an institutional virtual learning environment substantiate the reflections, seeking to trace difficulties and overcoming observed among students in their relations with music and their emotional states. The work seeks to delineate the possibilities and setbacks of connections on different interfaces, whether affective or technological, retrieving data on the impact of remote education the emotional states of this population. This time frame is divided into three parts and traces, in an optimistic approach, achievable paths in face of the unpredictability and instability of this new reality.
\end{abstract}

Keywords: Pandemic, Digital Culture, Emotions of Musicians, COVID-19. 


\section{Tempos transmutados}

Compositor de destinos

Tambor de todos os ritmos

Tempo tempo tempo tempo

Entro num acordo contigo

Tempo tempo tempo tempo

(Oração ao tempo (1979), Caetano Veloso)

Este ensaio crítico é um recorte temporal da pandemia no campo da música, buscando partilhar reflexões e experiências marcantes dessa quarentena vivenciada em 2020. São novos ciclos, imersos em noções de musicalidade e temporalidade profundamente impactadas pela quarentena no mundo: tempos dispersos, tempos suspensos, musicalidades abafadas, acolhidas, esquecidas ou manipuladas por mecanismos e universos digitais. Em decorrência da pandemia da doença do Coronavírus de 2019 (COVID-19) ${ }^{1}$, diferentes modos de se viver em sociedade precisaram ser encontrados, e a área cultural é seguramente uma das mais afetadas por esse fenômeno.

Um ano no qual o mundo se defrontou com uma nova realidade que, em muitos aspectos, parece surreal. O termo surreal é descrito como algo estranho, que transgride a verdade tangível, que beira ao absurdo ou que transcende o real (HOUAISS, 2001). Se alguém tivesse tentado prever um cenário de uma epidemia global dessa magnitude, que obrigasse uma parcela significativa da população mundial a manter o distanciamento social e o confinamento em suas residências, inclusive com milhões de escolas, universidades e teatros fechados em diferentes continentes, poderia ser taxado de fatalista e exagerado, numa história que flerta com roteiros de ficção científica.

No entanto, o ano de 2020 mostrou que sim, é necessário usar máscara, mesmo em modelo caseiro, pois ela diminui a potência de contaminação do vírus, como mostram diversos estudos (TAMINATO et al., 2020); é crucial promover estratégias de fortalecimento do distanciamento social limitando, em média, a 60\% da movimentação em períodos prévios ao acentuado contágio, de modo preventivo (AQUINO et al., 2020);

\footnotetext{
${ }^{1}$ Sigla utilizada utilizada para chamar a doença, decorrente de acrônimo elaborada na língua inglesa. Segundo a FIOCRUZ (2020): "Desde o início de fevereiro, a Organização Mundial da Saúde (OMS) passou a chamar oficialmente a doença causada pelo novo coronavírus de COVID-19. COVID significa Corona Virus Disease (Doença do Coronavírus), enquanto '19' se refere a 2019, quando os primeiros casos em Wuhan, na China, foram divulgados publicamente pelo governo chinês no final de dezembro.
} 
assim como é importante realizar um processo de desinfecção ao chegar em casa (DOREMALEN et al., 2020) - e sair somente em situação de extrema necessidade nessa quarentena mal feita do Brasil, que teima em reproduzir hábitos pouco saudáveis e sem fundamento científico no comportamento de algumas figuras públicas.

Harari (2020), ao refletir sobre a crise global desencadeada pela pandemia, entende que estamos nos defrontando com dois caminhos a escolher: a partir de recursos tecnológicos, um caminho possível de vigilância controladora ou de fortalecimento da autonomia cidadã; e sobre uma postura coletiva social, a escolha entre um isolamento nacionalista ou uma postura de solidariedade global.

Nosso país, lamentavelmente, tem demonstrado fazer as escolhas erradas. Como agravamento do quadro caótico no Brasil, o representante oficial da nação e seus seguidores, por afinidade, menosprezam a doença, minimizando seus riscos e desdenhando dos cuidados necessários para evitar o contágio (CANINEU; MUÑOZ, 2020), além de fazer declarações públicas hostilizando países cujas posturas sejam distintas. Enquanto governantes de países de diferentes perfis socioeconômicos se mantém firmes na orientação e proteção de sua população para a mitigação do avanço e danos da pandemia até a chegada e popularização de vacinas, como Austrália, Vietnã e Alemanha, no Brasil há uma condução negacionista que parece desprezar a vida. Após uma breve atuação do Ministério da Saúde, cujas comunicação transparente e ações cientificamente fundamentadas foram propostas nos primeiros meses de $2020 \mathrm{com}$ amplas parcerias técnico-científicas e implementação de recursos tecnológicos de ponta (OLIVEIRA et al., 2020), o órgão passou a contar com uma posição mundialmente criticada, que chegou a manter este ministério mais de 120 dias sem ministro, após sucessivas trocas. Em plena crise sanitária mundial, até o fim deste ano corrente não apresentava um plano consistente de vacinação da população numa visão negacionista. Essas posturas e decisões se refletem no cotidiano acadêmico de variadas formas.

$\mathrm{Na}$ condição de artistas, docentes e pesquisadores da área da música, percebemos o impacto negativo imediato que o distanciamento social e todo processo da quarentena vem causando no meio cultural. Em sua presença comovente e efêmera, a música ao vivo foi silenciada já nos primeiros dias da pandemia, sendo proibida por manifestações presenciais, assim como outros eventos do campo cultural que gerassem agrupamentos 
sociais. Por outro lado, a capacidade de conforto emocional que a música promove no processo de apreciação, encharcando o nosso cérebro de dopamina (CUERVO; ROSAT, 2018), se mostrou significativa para muitas pessoas.

Esses tempos transmutados nos desafiam a repensar o que Krenak (2019, p. 27) chamou de "[...] a experiência da nossa própria circulação pelo mundo, não como uma metáfora, mas como uma fricção". A ideia de contar uns com os outros, como defende Krenak, em tempos de pandemia, toma novas dimensões. Fazer música em conjunto, apresentar música para um público, ensinar e aprender música na relação entre mestre e aprendiz, entre colegas, educador e educando, entre parcerias colaborativas, enfim, agora, enfrenta os desafios do confinamento social e da desigualdade de acesso aos recursos tecnológicos, entre tantos outros.

Em nossos registros, seja nos ambientes virtuais de aprendizagem, seja em survey investigativo, encontramos depoimentos ${ }^{2}$ que nos fizeram refletir sobre a importância da música na vida antes, durante e pós-pandemia, vislumbrando espaços e sentidos que tomaria.

Em nossa universidade, o Ensino Remoto Emergencial (ERE) levou 5 meses para ser implementado (CEPE/UFRGS, 2020), deixando a comunidade acadêmica em tempo suspensivo, sem manutenção de vínculo pedagógico, cujas iniciativas isoladas eram informais e pessoalmente assumidas por docentes. $\mathrm{O}$ retorno às aulas em formato virtual após uma primeira pausa de meses em nossa instituição, trouxe relevante acolhimento emocional para alguns estudantes de graduação, embora saibamos de muitos casos de exclusão do acesso a tecnologias demandadas no ensino remoto.

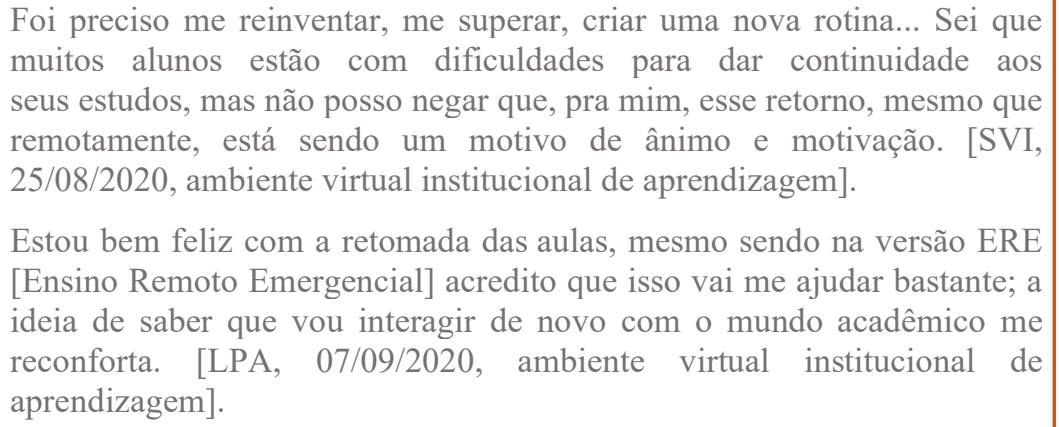

\footnotetext{
${ }^{2}$ Registrados em formato anônimo, com sujeitos diferenciados por siglas, em falas coletadas em fóruns públicos de discussão no ambiente virtual de aprendizagem (AVA) e nos formulários de pesquisa via Google Forms propostos nestes AVAs e em cursos de extensão. Os relatos serão apresentados envolvidos por uma borda, em fonte um pouco mais clara.
} 
Voltar às aulas, mesmo que no formato ERE, é um alívio e certamente me ajudará na saúde mental. [ASA, 25/08/2020, ambiente virtual institucional de aprendizagem].

[...] os dias ficam meio cinzas nesta situação de pandemia e tudo passa muito lento, penso que o retorno, mesmo que a distância, é positivo, traz a vontade que estava meio quebrada ou perdida [DUE, 18/08/2020, ambiente virtual institucional de aprendizagem].

Krenak (2019) já vinha nos alertando sobre a necessidade de valorizar as relações e as vivências como forma de dar sentido à vida, combatendo a apatia e a hostilidade diante do prazer na sociedade contemporânea:

\begin{abstract}
Nosso tempo é especialista em criar ausências: do sentido de viver em sociedade, do próprio sentido da experiência da vida. Isso gera uma intolerância muito grande com relação a quem ainda é capaz de experimentar o prazer de estar vivo, de dançar, de cantar. E está cheio de pequenas constelações de gente espalhada pelo mundo que dança, canta, faz chover (KRENAK, 2019, p. 26).
\end{abstract}

A importância da música e das artes em geral é destacada pela UNESCO (2020a) em suas manifestações oficiais, quando prediz que as artes, nas suas manifestações diversas "[...] são importantes para aumentar a criatividade e o pensamento crítico, para desenvolver uma apreciação estética elevada, para melhorar as habilidades de colaboração e para aumentar o entendimento no âmbito das culturas e também entre elas" (UNESCO, 2020a, p. 2).

Jovens integrantes do projeto de extensão "Orquestra São Francisco Conectada" - uma ação realizada na periferia a capital gaúcha que visa promover inclusão social através da música demonstra o poder mobilizador dessa linguagem (SEVERO; CUERVO, 2020) responderam a uma pesquisa sobre música e quarentena. É importante destacar o objetivo central deste projeto, que consiste em "criar, registrar e implementar estratégias inovadoras de fomento à conexão através da música em diferentes interfaces: conexão afetiva, conexão cognitiva, conexão sociocultural e conexão digital" (SEVERO; CUERVO, 2020, p. 2). Dos integrantes, $88 \%$ atribuíram índice 5 na escala de 0-5 sobre a importância da música em suas vidas, e 12\% índice 4. Uma das falas sintetiza as memórias afetivas positivas relacionadas à presença no grupo musical:

Eu entrei para a Orquestra São Francisco pois eu estava passando por um momento difícil e ficava muito tempo sozinha com os meus pensamentos. Depois que entrei eu fiquei melhor e feliz. [MES, 24/10/2020, Google Forms]. 
Sob diferentes pontos de vista, três depoimentos de estudantes da graduação ilustram o sentimento de conforto promovido pela música e a relevância do fazer coletivo:

[...] tenho valorizado muito o sentimento de estar em rede, mesmo à distância. Estar em contato com colegas tem sido fundamental (aliás, creio que a possibilidade de participar de algumas formações online tem contribuído para conhecer pessoas que talvez não tivesse oportunidade de encontrar ao vivo). [MHE, 20/08/2020, ambiente virtual institucional de aprendizagem].

Pra mim, quando se estabeleceu a quarentena de maneira forte foi bem aterrorizante. Fiquei bem abalado nos primeiros meses, e produzir e tocar música de maneira despretensiosa (em relação a demandas de trabalho ou estudo) foi, de muitas formas, uma boia no mar. Revi criações antigas, compus um pouco ali. Tirei músicas novas. [AHA, 21/09/2020, ambiente virtual institucional de aprendizagem].

Tenho a curiosa percepção de que a nossa realidade antes da quarentena ficou tão distante e que o que antes eu pensava em pesquisar não faria muito sentido hoje. Afinal de contas, nem estamos podendo tocar juntos. Mas sei também que tudo é muito intenso e transitório, como quando ficamos sem dormir noite após noite, com um bebezinho para amamentar e cuidar, e achamos que nunca mais vamos dormir uma noite de sono na vida. (KAS, 19/08/2020, ambiente virtual institucional de aprendizagem].

Esses tempos de quarentena têm me feito me relacionar com o piano de formas diferentes, inclusive compondo. Acredito que ter a música em nossas vidas neste momento se tornou (mais um) privilégio. Que saibamos aproveitá-lo. [BES, 29/08/2020, ambiente virtual institucional de aprendizagem].

O isolamento social tem se mostrado uma estratégia eficaz na contenção da pandemia, porém bastante desgastante para significativa parte da população, como explicam Bezerra et al. (2020) em sua pesquisa. Neste estudo, a maior parte dos indivíduos consultados relatou sentir estresse no ambiente doméstico em função do isolamento (56\%) e para $17 \%$ o isolamento tem sido muito acentuado o nível de estresse. Além disso, os autores observaram que os diferentes segmentos sociais sofrem de maneira diversa os impactos do isolamento. Esse achado reafirma a percepção de que, quanto mais precárias as condições de vida, alimentação e trabalho, mais penosa é a manutenção do isolamento social: "É notório, e os dados também revelaram, que as populações mais pobres já estão sofrendo um impacto maior do isolamento, especialmente em relação à renda" (BEZERRA et al., 2020, p. 2419). O Brasil já apresentava um cenário de extrema desigualdade social, para além, portanto, de estados emocionais abalados, problemas de saúde, insegurança alimentar, desemprego e de acesso à comunicação durante a pandemia. 
Em complemento, Albuquerque (2020), pesquisador dedicado a estudar a música nas periferias explica que, numa sociedade racializada, a pandemia afeta em muito maior magnitude a população negra, e muitos artistas negros têm sido obrigados a cumprir outros serviços de outras áreas para manutenção material básica.

Contudo, cabe lembrar que muitas manifestações seguiram no formato presencial, mesmo diante de uma pandemia mundial, como as mobilizações em eleições presidenciais nos EUA e municipais Brasil, ou os protestos contra a violência policial que vitima principalmente negros no mundo. Episódios brutais ocorridos nestes dois países como a morte de George Floyd, de Beto Freitas, da ativista negra Jane Beatriz e das primas Emilly e Rebecca, mostram que movimentos \#BlackLivesMatter e \#VidasNegrasImportam precisam mobilizar universos presenciais com o mesmo vigor que virtuais. Essas violências físicas e simbólicas nos mobilizam a pensar a sobrecarga psicológica da população negra no Brasil, diante de uma pandemia, confrontando-se com situações de precariedade de moradia, trabalho, alimentação e estudo.

O ambiente escolar e universitário, cursos livres e escolas de música públicas e privadas, professores e estudantes, apreciadores, produtores e todo set de cultura, incluindo artistas de palcos, festas e projetos culturais, enfim, se encontram bruscamente afetados por essa nova realidade desde os primeiros dias. Uma realidade que, primeiramente, estagnou e estarreceu essa população; depois, mais ou menos velozmente, impeliu comunidades inteiras a enfrentar seus medos: o acúmulo da sobrecarga emocional diante de uma quarentena forçada e as demandas do estudo e trabalho remotos causando a fadiga das telas. As palavras "o novo normal" e a necessidade de se "reinventar" passaram a ser corriqueiras nas discussões acadêmicas e midiáticas.

Os tempos cronológicos se chocam com os tempos transmutados da quarentena no organismo, refletindo-se em ciclos circadianos desorganizados: relatos expressam que períodos de sono e vigília, energia para compromissos síncronos ou assíncronos e disciplina diante das práticas musicais foram profundamente abalados pela pandemia e as exigências de distanciamento e confinamento social. 

O início da quarentena foi muito difícil para mim no sentido que eu tinha que mudar minha rotina, ficar dia inteiro em casa sem ir na faculdade, sem poder trabalhar, sem poder ver os amigos, os parentes e pior que não sabia e ainda não sei até quando iremos ficar nessa. Com o tempo aprendi e ainda estou aprendendo a lidar e a viver com essa situação. Passo a maior parte de meu tempo entre falar com a família [...], fazer o que eu gosto (música e dança) e cozinhar. [LPA, 07/09/2020, ambiente virtual institucional de aprendizagem].

No levantamento junto à orquestra juvenil, coletamos o seguinte depoimento sobre impactos da pandemia em sua vida musical:

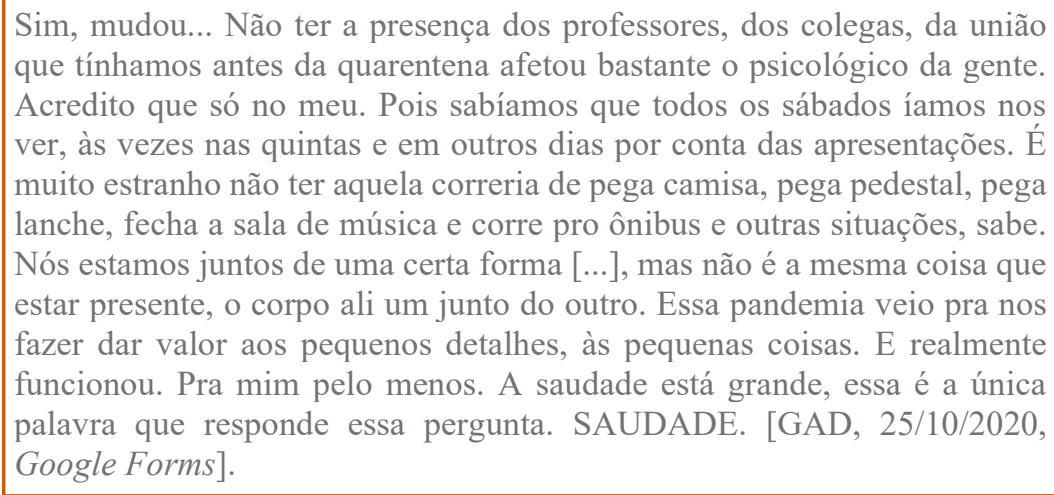

Sim, mudou... Não ter a presença dos professores, dos colegas, da união que tínhamos antes da quarentena afetou bastante o psicológico da gente. Acredito que só no meu. Pois sabíamos que todos os sábados íamos nos ver, às vezes nas quintas e em outros dias por conta das apresentações. É muito estranho não ter aquela correria de pega camisa, pega pedestal, pega lanche, fecha a sala de música e corre pro ônibus e outras situações, sabe. Nós estamos juntos de uma certa forma [...], mas não é a mesma coisa que estar presente, o corpo ali um junto do outro. Essa pandemia veio pra nos fazer dar valor aos pequenos detalhes, às pequenas coisas. E realmente funcionou. Pra mim pelo menos. A saudade está grande, essa é a única palavra que responde essa pergunta. SAUDADE. [GAD, 25/10/2020, Google Forms].

A música tem um poder mobilizador de sentimento, como recurso regulador de emoções, assim como de congregação social, amplamente discutido por diversos autores, como sintetiza Levitin (2010). No entanto, o mundo virtual impede o fazer musical coletivo, que desde as rodas em volta da fogueira, em tempos remotos, são tão importantes como atividade social. As canções de conforto, amizade, conhecimento, amor, religiosidade e divertimento explicam a natureza humana e sua história (LEVITIN, 2016), num mundo no qual não há notícia de grupo social ou região sem a manifestação da musicalidade. 


\section{Tecnofobia e fadiga}

O cérebro eletrônico comanda

Manda e desmanda

Ele é quem manda

Mas ele não anda

Faz quase tudo

Mas ele é mudo

Ele é quem manda

Mas ele não anda

(O cérebro eletrônico (1969), Gilberto Gil).

Como diz Gil (1969), o computador "faz quase tudo, mas ele é mudo". O confinamento social e as relações mediadas por máquinas dominam este período obscuro da história. A humanidade sofre com a frieza do distanciamento social. Também se nota que o período da quarentena demandou de forma imediata domínios tecnológicos e recursos materiais dos quais não se dispunha em geral. Além disso, o desenvolvimento de novas tecnologias muitas vezes já não vinha necessariamente acompanhado da plena aceitação desses novos recursos, nem da sensação de conforto em relação a eles por significativa parte da população em geral.

Dinello (2005) aborda o conceito de Tecnofobia, pontuando que se trata de um fenômeno que sugere aversão, não gostar, ou suspeição da tecnologia - e não um medo neurótico, irracional ou ilógico (DINELLO, 2005, p. 8). O autor critica a visão utópica associada a esses recursos, evidenciando os vieses e os riscos do desenvolvimento tecnológico desenfreado (muitas vezes decorrente de intenções bélicas ou exploratórias) através da análise de obras da cultura pop as quais expressam nossos receios digitais mais profundos, por vezes antecipando futuros distópicos, assombrosos, permeados por ciborgues, manipulação gênica e servidão às máquinas (DINELLO, 2005). Por outro lado, Gohn (2007, p. 163) observa essa reação como um produto da insegurança de certos indivíduos frente ao novo, manifestando-se através da opção pelo distanciamento de aparelhos digitais. Para ele, esse fenômeno decorre da falta de familiaridade com o manuseio dos novos dispositivos e do temor à falha durante sua operação - destacando, por conseguinte, o protagonismo das gerações mais antigas para a sua perpetuação: 
[A preferência pelo distanciamento dos aparelhos digitais] está muitas vezes relacionada ao medo de errar, causado pela incompreensão do funcionamento dos mecanismos e agravado pelo fato de que gerações mais jovens sempre apresentam maiores facilidades no manuseio das novas tecnologias". (GOHN, 2007, p. 163).

Em experiência docente vinculada ao curso de música na modalidade a distância na Universidade entre os anos de 2009 e 2012, Cuervo (2012) apontou uma série de elementos problemáticos manifestados pelo seu público discente. Em suas investigações, encontrou uma quantidade significativa de estudantes que estavam passando por dificuldades, como sentimento de isolamento pela mediação das máquinas e mesmo falta de capacitação em inclusão digital para a adoção de recursos tecnológicos referentes às demandas de um curso dessa natureza, refletindo-se em evasão e reprovação que chegava a índices de 90\% em alguns polos (CUERVO, 2012). É de se imaginar que a música no ensino remoto em caráter emergencial no período da quarentena some esse tipo de problema a outros tantos, pois foram raras e isoladas as iniciativas de promover inclusão digital dentre estudantes de graduação e ainda mais raras recursos de suporte na esfera pública da saúde mental.

Um depoimento coletado entre estudante de graduação em música nos provoca a pensar sobre o ensino remoto e as relações com as tecnologias:

Eu sempre fui contra as aulas virtuais antes da pandemia, porque eu achava
(e ainda acho) que a arte não se pode realizar sem o contato físico, como o
trabalho em grupo. Quando começou a pandemia eu fiquei muito perdido,
mas com o tempo cheguei a perceber que poderia me acostumar a trabalhar
em casa em frente de um computador. Eu nunca estive familiarizado com
o ensino a distância, e foi muito difícil encontrar um rumo para poder
estudar. [YMA, 21/10/2020, ambiente virtual institucional de
aprendizagem].

Em outra faixa etária, a adolescente integrante da orquestra também manifesta descontentamento com o fazer musical remoto, especialmente pela falta de convívio social:

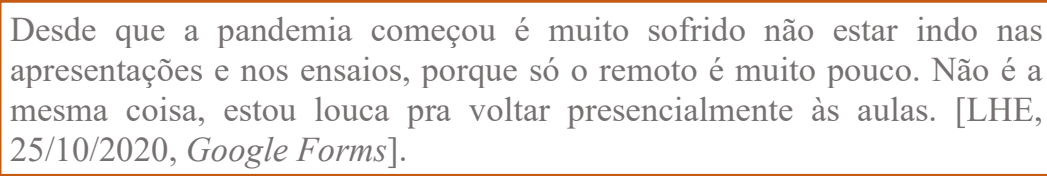

Gohn (2007) nos lembra que, no campo da música, os avanços tecnológicos trouxeram muitas facilidades. Contudo, alerta mais uma vez que estas facilidades são muito mais populares entre os mais jovens, enquanto professores acabam tendo mais 
resistência às novas tecnologias, como programas de notação musical: "Os alunos, em contrapartida, se atiram nas chances de experimentar novos softwares, sempre buscando expandir seus domínios sobre as novidades (GOHN, 2007, p. 163).

O levantamento do projeto "Orquestra São Francisco Conectada" mostrou que 72\% dos estudantes utiliza o celular para estudar música e 96\% preferem o WhatsApp como recurso de comunicação, recebimento de dicas, orientações e materiais sobre a Orquestra (SEVERO; CUERVO, 2020). Já o Google Meet é a plataforma predileta dos estudantes para os encontros online (64\%), seguida do Zoom (20\%), sendo a segunda melhor avaliada pela regente, em termos de qualidade sonora (SEVERO; CUERVO, 2020).

Gohn (2007, p. 163) também já observava que "as incertezas decorrentes das tecnologias digitais e das redes eletrônicas representam um dos maiores desafios para os indivíduos na atualidade", relembrando importantes episódios na história da música recente nos quais pôde ser visualizada a manifestação incontestável da Tecnofobia, como a luta contra a indústria dos fonógrafos e a mobilização frente ao livre compartilhamento de músicas MP3 através da internet (GOHN, 2007, p. 166).

Para Gohn (2007), portanto, a Tecnofobia consiste em um fenômeno originalmente subjetivo, moldado pelos sentimentos experimentados por algumas pessoas frente às mudanças trazidas pelas tecnologias - uma reação humana à realidade mutante. Embora observe que a Tecnofobia ocorre enquanto fenômeno geracional recorrente, o autor reforça seu aspecto individual, descrevendo-a de maneira semelhante a quem descreve um traço de personalidade, ou uma característica pessoal:

\section{[...] o tecnófobo se recusa a ultrapassar os limites do essencial, aprendendo a lidar somente com o estritamente necessário para sobreviver no mundo moderno. [...] Apesar das interfaces amigáveis que cada vez mais popularizam os programas digitais, as máquinas ainda são consideradas enigmas impossíveis de serem desvendados (GOHN, 2007, p. 172).}

No campo da educação superior, surgem conceitos tão fascinantes quanto desconhecidos, que antes faziam parte do cotidiano de uma pequena parcela da população brasileira no que diz respeito a estudos e práticas pedagógicas e artísticas em educação musical. De forma súbita, artistas e educadores da modalidade presencial tradicional passaram a atuar como professores conteudistas, pesquisadores, produtores e tutores de si e consigo mesmos e, em muitos casos, sequer contando com uma plataforma de aprendizagem adequada para utilizar, principalmente considerando as especificidades da 
música: qualidade sonora e sincronicidade no fazer musical coletivo. Depoimentos de discussões em nossos ambientes virtuais confirmam essa visão:

Também tenho dado atenção à prática musical, tocando repertórios que me
interessam e explorando um pouco a composição. Sinto falta de ter tempo
para tocar quando na minha rotina normal, então essa tem sido uma
oportunidade (inclusive para performances ao vivo com finalidade de
acolhimento em reuniões, formações... da minha equipe de trabalho - isso
é bem gratificante). Apesar disso, espero ansiosamente pelo fim desta
pandemia, que cheguemos até lá com saúde física e mental e que possamos
retomar nossa vida "normal". [MHE, 20/08/2020, ambiente virtual
institucional de aprendizagem].
O início foi bem difícil, alguns planos tiveram que ser adiados, e eu, que
sempre fui um pouco alheio às tecnologias, tive que me adaptar e investir
para produzir conteúdo ou ao menos tentar manter uma prática musical.
Agora um pouco mais adaptado, estou participando de editais de incentivo
à produção de conteúdo digital, participando de vídeos colaborativos de
amigos de outros estados e criando encontros musicais digitais via Zoom
com um dos grupos que faço parte, nos quais a gente passa um "chapéu
virtual". [MHE, 25/08/2020, ambiente virtual institucional de
aprendizagem].

Com a instantaneidade emergencial de conteúdos virais, com perdão da analogia, musicistas e educadores musicais se viram diante de novas e estressantes demandas, sem tempo para sua capacitação, sem recursos materiais de apoio: aprender a fazer uma videoaula ou um podcast, a manipular fones, microfones, webcams, cabos e... produzir conteúdo em formato digital. De modo geral, não houve iniciativas institucionais ou governamentais, nas esferas pública ou privada, para que fossem adquiridos equipamentos e pacotes de conexão com preços acessíveis para educadores e educandos, como exemplifica este relato:

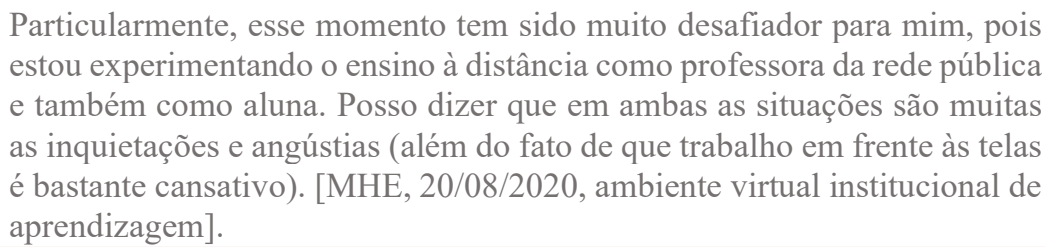

A tão alardeada e imediatista necessidade de se reinventar, de ter autonomia, de ser criativo, não cabe no mesmo espaço de tempo de ser reflexivo, crítico e solidário. Ao mesmo tempo em que nós aprendíamos a configurar um software de áudio para uso com microfone de lapela, buscávamos notícias do estudante monitor que havia testado positivo para COVID-19. No mesmo dia que explorávamos ferramentas para enriquecer a configuração de questionários do Ambiente Virtual de Aprendizagem Moodle Colaboração, combinávamos a entrega de cesta básica a estudante refugiada em situação de vulnerabilidade. E assim foram dias, semanas e meses no contexto da música e da 
cultura, área que já vinha empobrecida pela precariedade das leis trabalhistas, pela destruição das leis de incentivo fiscal à cultura, pelo crescente desemprego e desvalorização da área especialmente desde o golpe que resultou na retirada da presidente eleita.

Gohn (2007, p.172) acredita que a Tecnofobia está fadada ao fracasso, observando que o telefone celular, amplamente utilizado hoje, fora inicialmente objeto de rechaço e resistência - inclusive por muitos daqueles que se beneficiam de sua praticidade atualmente. Demo (2009, p. 5), contudo, observa que tanto a Tecnofilia, quanto a Tecnofobia (termos respectivamente empregados, segundo o autor, para se referir a quem aprecia em excesso as novas tecnologias, ou a quem as aprecia de menos) consistem em posicionamentos excessivos, os quais tomam o protagonismo do fato consumado de que as novas tecnologias já se encontram difundidas e enraizadas - em consonância com Gohn. Assume, portanto, uma posição mais ponderada quando questiona a aceitação do educador em relação a esses recursos e a recusa dos tecnófobos a eles, sem esquecer os riscos associados ao uso de novos dispositivos (DEMO, 2009).

A solidão que pode dominar o ambiente virtual foi discutida por Rufus, citado por Gohn (2007). Embora em seu estudo sobre solidão e internet o pesquisador tenha encontrado que "A internet legitima a solidão [...] e faz o ato de ficar sozinho parecer normal” (RUFUS, apud GOHN, 2007, p. 167), permite aos usuários solitários realizar atividades sem sofrer. Para esse pesquisador, a internet também democratiza o acesso a diversos materiais pelo mundo todo, antes restritos a limitações geográficas, como bibliotecas, ampliando as possibilidades de conexões com o mundo exterior.

Krenak (2020) nos alerta que a sociedade urbana chegou a tal ponto que as pessoas sofrem com solidão mesmo em grandes metrópoles de 2 milhões de habitantes, e que essa perspectiva precisa mudar. Em suas palavras: "Essa experiência de uma consciência coletiva é o que orienta as minhas escolhas" (2020, p. 39). Em relação aos indivíduos indígenas de diferentes nações, Krenak (2020) explica que "Não conheço nenhum sujeito de nenhum povo nosso que saiu sozinho pelo mundo. Andamos em constelação" (2020, p. 39).

Estudos recentes concernentes a estados emocionais no período da quarentena têm demonstrado um aumento de casos, crises e relatos de depressão, ansiedade e tristeza da 
população (BARROS et al, 2020). Pesquisa de Barros e colaboradores (2020), sobre saúde mental da população brasileira durante a pandemia, constatou que as altas prevalências de depressão, ansiedade, problemas do sono e outros distúrbios demonstram a premência de investimentos de recursos humanos e materiais nesse tema.

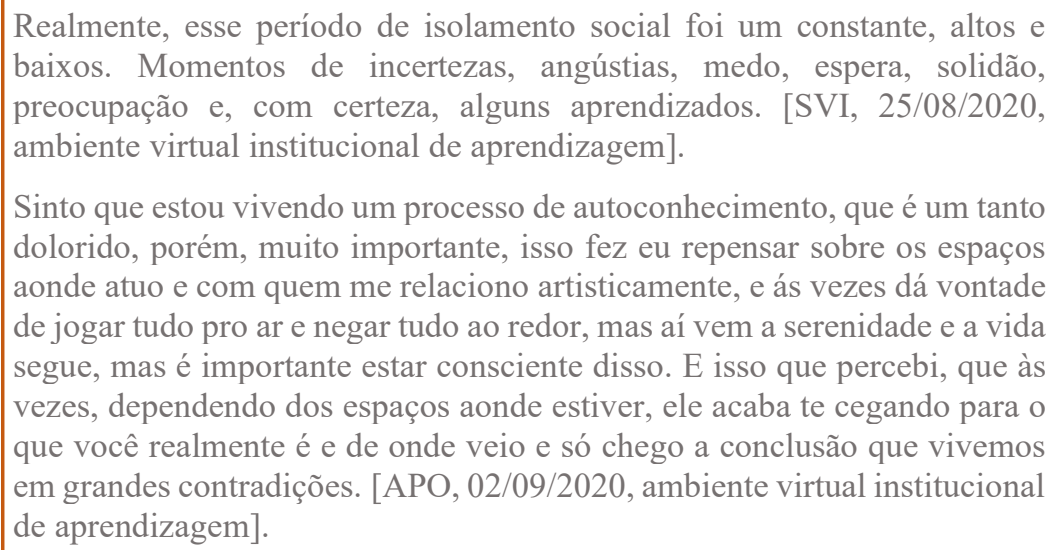

Revisitando a pesquisa de Gohn (2007, p. 171), encontramos que: "tais medos frequentemente são decorrentes das incertezas e dúvidas que cercam a utilização dos equipamentos digitais, e não de problemas constantes a partir de experiências pessoais prolongadas". O que percebemos é que, se já existia uma certa Tecnofobia por parte da comunidade acadêmica de música envolvendo as práticas musicais, com o ensino remoto implementado houve uma soma de fatores, decorrendo disso a fadiga das telas e as patologias comuns a ela.

A enorme quantidade de energia despendida durante o uso das novas tecnologias evidencia a sua lógica tecnocêntrica, apontada por Bauer [s.d.] como um dos empecilhos identificados por educadores no emprego das tecnologias educacionais. Como se não bastasse, a efemeridade desses recursos digitais exige que, além de multifacetado, o musicista seja também um contínuo estudante - não mais apenas da prática musical, mas também da prática digital. Em tempos de quarentena, nos quais se intensifica o uso dos dispositivos digitais, é natural esperar que a "Fadiga das Telas" passe a acompanhar o musicista, juntamente com a "Lesão por Esforço Repetitivo" e a "Perda Auditiva Induzida por Ruído", nas consultas médicas.

A esses fenômenos, soma-se o que ficou conhecido recentemente por "fadiga da quarentena", fase na qual o cidadão comum já se encontra esgotado dos procedimentos inerentes à pandemia, como uso de equipamentos de proteção individual e desinfecção 
sistemática dos espaços de convívio, quebrando a adoção de protocolos e colocando-se em risco por erros perceptivos do contexto (MOLITERNO, 2020).

O ser humano é um ser de superação, e o conceito de plasticidade neuronal é uma prova disso, pois a cada nova aprendizagem o cérebro se reconfigura e enriquece em conexões e redes (CUERVO; ROSAT, 2018). O cérebro humano é engajado em quase todas as suas regiões conhecidas pela ciência, assim como quase todos os subsistemas nele existentes (LEVITIN, 2010). Contudo, para que esse processo biológico ocorra, é preciso algo que foi tirado de docentes e estudantes, "da noite para o dia": tempo. O tempo de aprendizado das novas tecnologias, o tempo de aquisição de recursos materiais necessários, o tempo de garantir, prioritariamente, segurança alimentar e saúde emocional às classes docentes e discentes, não existiu. Não houve tempo de reflexão, de construção dialógica, de colaboratividade.

Temos problematizado, ainda, a influência das modalidades de atuação remota em nossas práticas musicais em substituição dos encontros presenciais, acreditando que, talvez, haja inclusive alterações da natureza e do conteúdo moldados pelos serviços desses aplicativos. Ressaltamos pontos como as limitações de tempo de encontro, na qualidade de áudio e ausência de contato físico, sincronicidade prejudicada, dispositivos pessoais por vezes obsoletos ou modelos aquém das demandas, irregularidade das conexões de internet e espaço improvisado no ambiente residencial como alguns dos maiores obstáculos do fazer musical em tempos de quarentena.

\section{Musicalidades que fluem}

Se o mundo andar pra trás Vou escrever num cartaz A palavra rebeldia

Se a gente desanimar Eu vou colher no pomar A palavra teimosia

(Samba da utopia (2018), Jonathan Silva).

A cultura digital, por si só, já vinha transformando as práticas musicais, especialmente a partir do século 20. Possibilidades performáticas antes limitadas a 
manifestações efêmeras da interpretação ao vivo passaram a ter diversas possibilidades de registro que passariam a transcender, em muito, a partitura tradicional pentagramática.

A necessidade da arte e do fazer musical vem sendo explicada pela necessidade de pertencimento e coesão social desde tempos muito remotos em todos os grupos sociais conhecidos (DISSANAYAKE, 2011; LEVITIN, 2010; 2016; HURON, 2012). A cultura digital entra nesse contexto como ferramenta e recurso de inclusão e exclusão, de portabilidade e ubiquidade, mantendo a relevância da música nas sociedades ao longo de sua história longeva (CUERVO, 2016).

Parece-nos fundamental observar a necessidade de problematização de das novas tecnologias, muitas vezes relembrando o quão desgastante é o domínio de seu universo o qual exige permanente atualização. Nós entendemos que se deve prestar atenção às dificuldades, às limitações e aos questionamentos relativos às tecnologias. Além disso, deve-se problematizar a incorporação acrítica de novos recursos tecnológicos em detrimento de outros, pois, em uma cultura de descarte, a inserção dos novos dispositivos não ilustra apenas a substituição do antigo pelo novo, como argumenta Cuervo:

\begin{abstract}
A permanente postura de abertura ao novo não significa, de forma alguma, o rejeite do que veio antes, inclusive em termos de tecnologias. Promover o descarte de ideias e produções anteriores sem problematização frente ao novo é uma espécie de fortalecimento do conceito de obsolescência programada também no campo epistemológico. Trata-se de uma analogia cruel (CUERVO, 2019, p. 128).
\end{abstract}

Considerando que a internet é a ponte de uma rede mundial de computadores e dispositivos móveis que liga e promove a comunicação de docentes e estudantes, assim como de docentes e sites, materiais didáticos e recursos para a construção destes, enfim, o acesso a uma conexão de banda larga ou internet móvel de qualidade é um ponto crucial.

Em música, estamos falando da necessidade de se produzir, editar, projetar e apreciar áudios, vídeos, textos etc. A Recomendação sobre Recursos Educacionais Abertos (REA), adotada pela Conferência Geral da UNESCO (2019), enfatiza a necessidade de disponibilizar ambientes de aprendizagem sustentáveis e inclusivos por meio do uso de tecnologias de código aberto para todos os alunos. Seja em contextos formais ou ambientes informais, a UNESCO defende o acesso efetivo, inclusivo e igualitário a REA de qualidade. Esses recursos atendem também às diferentes formas de 
deficiência e mobilizam tecnologias existentes e conteúdos digitais com o intuito de considerar as necessidades das pessoas com deficiência.

Para propor caminhos possíveis a serem trilhados na música em tempos de pandemia, é preciso partir do pressuposto que toda classe docente tem condições materiais, sanitárias e emocionais mínimas de trabalho, num cenário ideal hipotético. $\mathrm{O}$ lema da UNESCO (2020b), em que "tudo significa tudo" (all meaning all, numa tradução direta), aponta diretrizes no sentido de prover mecanismos de apoio, capacitação e recursos para profissionais da educação. A Unesco (2020b) ressalta um conjunto de procedimentos que abrem defendendo a importância de investimentos em suporte psicossocial e passa por iniciativas de democratização e barateamento de recursos digitais para ampla utilização, seja off-line, seja em celulares básicos. Essas decisões exigem o exercício individual e coletivo de empatia, de considerar o direito de inclusão de outro indivíduo e grupos sociais menos favorecidos.

Talvez o desafio que se imponha seja a promoção de integração e coesão social em tempos e espaços de confinamento e distanciamento social. No meio da música, no qual se destacam as atividades da performance e da educação - ambas entrelaçadas em ações comunicativas e interativas - redes sociais ganharam destaque como espaços de partilha. Sua difusão foi acompanhada da criação de novas maneiras de se exercer a musicalidade e de ensiná-la.

O cerne da questão, talvez, consista em identificar e possibilitar recursos de oferta de capacitações promovidas em inclusão digital, apoio psicológico e fisioterapêutico, além de oferecimento equânime de recursos materiais, e outros elementos que ainda são tão raros no ambiente acadêmico de música.

Como tão bem nos alertam Krenak (2020) e Harari (2020), é preciso tomar o caminho da coesão social, pensar coletivamente em substituição ao individualismo. Como provoca Krenak (2020, p. 104) sobre o egoísmo humano: “[...] eu não vou me salvar sozinho de nada, estamos todos enrascados. E, quando eu percebo que sozinho não faço a diferença, me abro para outras perspectivas." Para ele, é na mobilização pelo outro que possibilita a construção de novas compreensões sobre a própria existência e a relação com a Terra (KRENAK, 2020). Enquanto isso, Harari (2020) vislumbra uma perspectiva de mudança de posição global: 
[...] não há necessidade de reagir propagando ódio, ganância e ignorância. Podemos reagir gerando compaixão, generosidade e sabedoria. Podemos optar por acreditar na ciência, e não em teorias conspiratórias. Podemos optar por cooperar com os outros em vez de culpá-los pela pandemia. Podemos optar por compartilhar o que temos em vez de apenas acumular mais para nós mesmos. Reagindo assim, de forma positiva, será muito mais fácil lidar com a crise, e o mundo pós-COVID-19 será muito mais harmonioso e próspero (HARARI, 2020, p. 9).

Krenak (2020) defende que precisamos escapar dessa visão utilitária da vida, como se o trabalho e a civilização fossem os únicos sentidos da existência. Esse pensador nos provoca a "atravessar o deserto" ao invés de fugir dele: "[...] O que nos resta é viver as experiências, tanto a do desastre quanto a do silêncio" (KRENAK, 2020, p. 116). Pensando essa travessia atrelada ao conceito de musicalidade como a geração de sentido através do fazer musical e lembrando que a expressividade do discurso musical está amalgamada ao seu contexto sociocultural e biológico (CUERVO, 2016), no mundo em quarentena e pós-pandemia, as musicalidades se veem transformadas.

Com este ensaio reflexivo não tivemos a intenção de promover um panorama de estratégias ou de previsões do universo musical após a pandemia. Contudo, singelamente resta-nos registrar nosso desejo de valorizar e de intensificar as conexões possíveis, de forma muito transcendente ao contato físico ou mediado por máquinas. Que o afeto possa nortear nossas ações, que a empatia e a expectativa do fazer musical coletivo, interativo, dialógico e prazeroso possa marcar essas novas musicalidades em novos tempos que surgem a partir da experiência dolorosa e transformadora da quarentena.

Que a música possa transcorrer em sua potência de fruição, em resgate de afetos, mobilização de causas sociais, protesto, lamento, celebração. Em ruídos e pausas. Que possamos nos confortar com a música em nosso bem estar, mas que também possamos promover o processo de tomada de consciência social através dela. 


\section{Referências}

ALBUQUERQUE, GG. Radar Sonoro: As desigualdades da pandemia e o pluriverso da música negra. 21/10/2020. Disponível em: https://www.sescsp.org.br/online/artigo/14813_RADAR+SONORO+AS+DESIGUALDADES+ DA+PANDEMIA+E+O+PLURIVERSO+DA+MUSICA+NEGRA. Acesso em: 01.12.2020.

AQUINO, Estela M. L.; SILVEIRA, Ismael S.; PESCARINI, Julia M. Et al. Medidas de distanciamento social no controle da pandemia de COVID-19: potenciais impactos e desafios no Brasil. Ciência \& Saúde Coletiva, v. 25 supl. 1. Rio de Janeiro, Jun. 2020. E-pub, 5 Jun, 2020. Disponível em: http://dx.doi.org/10.1590/1413-81232020256.1.10502020. Acesso em 05/11/2020.

BARROS, Marilisa Berti de A. Relato de tristeza/depressão, nervosismo/ansiedade e problemas de sono na população brasileira adulta durante a pandemia de COVID-19. Revista Epidemiologia e Serviços de Saúde, v. 29, n. 4, Brasília, 2020. Disponível em: https://www.scielo.br/scielo.php?pid=S2237-96222020000400311\&script=sci_arttext https://doi.org/10.1590/s1679-49742020000400018. Acesso em 06/12/2020.

BAUER, William I. Music Learning and Technology. New Directions, v.1, [s.d.]. Disponível em: https://www.newdirectionsmsu.org/issue-1/bauer-music-learning-and-technology/. Acesso em: 20 de nov. de 2020 .

BEZERRA, Anselmo C. V.; DA SILVA, Carlos E. M.; SOARES, Fernando R. G.; DA SILVA, José A M. Fatores associados ao comportamento da população durante o isolamento social na pandemia de COVID-19. Revista Ciência e saúde coletiva, Rio de Janeiro, v. 25, supl. 1, p. 24112421, Jun. 2020. Disponível em: \&lt;http://www.scielo.br/scielo.php?script=sci_arttext\&amp;pid=S141381232020006702411\&amp;lng=en\&amp;nrm=iso\&gt;. Acesso em: 17 de nov. 2020.

CANINEU, Maria Laura; MUÑOZ, César. COVID-19 chega a Bolsonaro - O presidente desconsidera as recomendações da OMS mesmo após teste positivo. 08/07/2020. Disponível em: https://www.hrw.org/pt/news/2020/07/08/375737 Acesso em: 17 de nov. 2020.

CEPE - CONSELHO DE ENSINO, PESQUISA E EXTENSÃO da UFRGS. Resolução n. 25/27 de julho de 2020. Porto Alegre: Universidade Federal do Rio Grande do Sul, 2020. Disponível em: http://www.ufrgs.br/cepe/res-025-ensino-remoto-emergencial-ere-versao-pagina. Acesso em: 16 de nov. 2020.

CUERVO, Luciane. Educação musical e a ideia de arquiteturas pedagógicas: práticas na formação de professores da geração "nativos digitais". Revista da ABEM, Londrina, v. 20, n. 29, p. 62-77, jul/dez. 2012. Disponível em: http://abemeducacaomusical.com.br/revistas/revistaabem/index.php/revistaabem/article/viewFil e/91/76 Acesso em: 15 nov. 2020.

CUERVO, Luciane. Musicalidade da performance na cultura digital: estudo exploratóriodescritivo sob uma perspectiva interdisciplinar. Tese (Doutorado Informática na Educação). Universidade Federal do Rio Grande do Sul, Porto Alegre, 2016.

CUERVO, Luciane. Educação musical e novas tecnologias digitais: recursos e estratégias no contexto do canto e da flauta doce. Orfeu, [S. 1.], v. 4, n. 1, p. 120-150, 2019. DOI: 10.5965/2525530404012019120. Disponível em: <https://periodicos.udesc.br/index.php/orfeu/article/view/1059652525530404012019120>. Acesso em: 17 nov. 2020. 
CUERVO, Luciane; ROSAT, Renata M. Abordagem interdisciplinar entre Música e Neurociências: estratégias de fomento e inserção curricular no ensino superior. Orfeu, v. 3, n. 1, jul. 2018, p. 187-196. Disponível em: $<$ http://www.revistas.udesc.br/index.php/orfeu/article/view/1059652525530403012018172/901 $0>$.

DEMO, Pedro. Tecnofilia \& Tecnofobia. Boletim Técnico do Senac: Revista da Educação Profissional, Rio de Janeiro, v. 35, n. 1, jan./abr. 2009. Disponível em: $<$ https://www.bts.senac.br/bts/article/view/251/233>. Acesso em: 11/12/2020.

DINELLO, Daniel. Technophobia!: Science Fiction Visions of Posthuman Technology. 1 ed. Austin, TX: University of Texas Press, 2005.

DISSANAYAKE, Ellen. Homo Musicus: Are humans predisposed to be musical? In: ENCUENTRO CIENCIAS COGNTIVAS LA MÚSICA, 10., 2011, Buenos Aires. Musicalidad Humana: debates actuales en Evolucion. Desarrolo y cognición e implicancias socio-culturales. Buenos Aires: SACCOM, 2011, p. 17-21.

DOREMALEN, Neeltje va; TRENTON, Bushmaker; MORRIS, Dylan. Aerosol and surface stability of HCoV-19 (SARS-CoV-2) compared to SARS-CoV-1. The New England Journal of Medicine. DOI: https://doi.org/10.1101/2020.03.09.20033217.

FIOCRUZ - FUNDAÇÃO OSWALDO CRUZ. Por que a doença causada pelo novo vírus recebeu o nome de COVID-19? Rio de Janeiro: FIOCRUZ, 2020. Disponível em: $<$ https://portal.fiocruz.br/pergunta/por-que-doenca-causada-pelo-novo-virus-recebeu-o-nomede-COVID-

19\#: :text=COVID $\% 20$ significa $\% 20$ COrona $\% 20$ VIrus\%20Disease,chin $\%$ C3\%AAs $\% 20$ no $\% 20$ final\%20de\%20dezembro.> Acesso em: 08 de nov. 2020.

GIL, Gilberto. "O cérebro eletrônico" (letra e música). GEge Edições/Preta Music (EUA \& Canadá), 1979. Disponível em: https://gilbertogil.com.br/ Acesso em 20/11/2020

GOHN, Daniel. Tecnofobia na música e na educação: origens e justificativas. Opus, Goiânia, v. 13, n. 2, p. 161-174, dez. 2007. Disponível em: $<$ https://www.anppom.com.br/revista/index.php/opus/article/view/308/282>. Acesso em: 12 nov. 2020.

HARARI, Yuval Noah. Notas sobre a pandemia e breves lições para o mundo pós-coronavírus. São Paulo: Companhia das Letras, 2020.

HOUAISS, Antônio e Villar. "Surreal" (verbete). In: Dicionário Eletrônico Houaiss da Língua Portuguesa. Editora Objetiva, 2001.

HURON, David. Um instinto para a música: seria a música uma adaptação evolutiva? Em Pauta, Porto Alegre, v. 20, n. 34/35, p.49-84, jan./dez. 2012.

KRENAK, Ailton. Ideias para adiar o fim do mundo. São Paulo: Companhia das Letras, 2019.

KRENAK, Ailton. A vida não é útil. São Paulo: Companhia das Letras, 2020.

LEVITIN, Daniel. A música em seu cérebro: a história de uma obsessão humana. São Paulo: Civilização Brasileira, 2010. 
LEVITIN, Daniel. The World in Six Songs: How the Musical Brain Created Human Nature. New York: Penguin, 2016.

MOLITERNO, Danilo. "Fadiga da quarentena": mecanismo psicológico incentiva o abandono do confinamento. Jornal da USP, 30/07/2020. Disponível em: https://jornal.usp.br/atualidades/fadiga-da-quarentena-mecanismo-psicologico-incentiva-oabandono- do-confinamento/ Acesso em 21 nov. 2020.

OLIVEIRA, Wanderson Kleber; DUARTE, Elisete; FRANÇA, Giovanny V.A.; GARCIA, Leila Posenato. Como o Brasil pode deter a COVID-19. Epidemiologia e Serviços em Saúde, Brasília, 29(2):e2020044, 2020. Disponível em: https://www.scielo.br/pdf/ress/v29n2/2237-9622-ress-2902-e2020044.pdf Acesso em 05/10/2020.

SEVERO, Keliezy; CUERVO, Luciane. Projeto Orquestra São Francisco Conectada: uma rede de inclusão sociocultural e de colaboratividade através da música. Projeto submetido ao Prêmio Fundação Péter Muranyi 2021 [manuscrito não publicado], outubro/2020 indicado pela Universidade Federal do Rio Grande do Sul. Porto Alegre: UFRGS, 2020.

SILVA, Jonathan. "Samba da utopia". (letra e música). 2018. Disponível em https://www.youtube.com/watch?v=KDXX7m3iBzc. Acesso em 20/11/2020.

TAMINATO, M.; MIZUSAKI-IMOTO, A.; SACONATO, H.; FRANCO, E. S., PUGA, M. E.; DUARTE, M. L. et al. Máscaras de tecido na contenção de gotículas respiratórias - revisão sistemática. Acta Paul Enfermagem. [online], 2020, v. 33. E-pub Jun. 08, 2020. ISSN 1982-0194. https://doi.org/10.37689/acta-ape/2020ar0103.

DOI http://dx.doi.org/10.37689/actaape/2020AR0103.

UNESCO. Recommendation on Open Educational Resources, 2019. Disponível em: https://unesdoc.unesco.org/ark:/48223/pf0000370936. Acesso em 30/11/2020.

UNESCO. Unesco celebra o poder da arte e da educação em todo o mundo. 25/05/2020a. Disponível em: https://pt.unesco.org/news/unesco-celebra-o-poder-da-arte-e-da-educacao-emtodo-o-mundo. Acesso em 10/11/2020.

UNESCO. Relatório de monitoramento da educação global 2020: Inclusão e educação: tudo significa tudo. 2020b. Autor corporativo: ISBN: 978-92-3-100388-2. Disponível em: https://unesdoc.unesco.org/ark:/48223/pf0000373718/PDF/373718eng.pdf.multi.

VELOSO, Caetano. "Oração ao Tempo" (música e letra). Álbum Cinema Transcendental, Philips LP 6349 436, 1979. Disponível em: http://www.caetanoveloso.com.br/. 
